Dr John Cusbert

Department of Philosophy,

Oxford University

A/Prof Kristie Miller

Department of Philosophy,

The University of Sydney

\title{
The unique groundability of temporal facts
}

\section{Abstract}

The A-theory and the B-theory advance competing claims about how time is grounded. The A-theory says that A-facts are more fundamental in grounding time than are B-facts, and the B-theory says the reverse. We argue that whichever theory is true of the actual world is also true of all possible worlds containing time. We do this by arguing that time is uniquely groundable: however time is actually grounded, it is necessarily grounded in that way. It follows that if either the Atheory or the B-theory is actually false, then it is necessarily false.

\section{Introduction}

In this paper we suggest that a helpful way to understand the dispute between Atheorists and B-theorists is in terms of how they see the relative fundamentality of the Aand B-series. In particular, we will argue that the A-theory is best understood as the view that what we call A-facts are more fundamental in grounding temporal facts, than are what we call B-facts.

We will not try to establish which of these theories is true, either in the actual world or in other possible worlds. Instead, we will argue that whichever theory is true of the actual world, it is also true of all possible worlds containing time. This is important since, of late, the orthodoxy that metaphysical theses are, if true, necessarily true, has come under significant pressure. ${ }^{1}$ Furthermore, there is special reason to be sceptical of such necessitarian claims concerning the nature of time. McTaggart-style arguments, which are designed to show that the A-theory is internally inconsistent (and hence necessarily false), have not been widely accepted, and there are no analogous arguments against the Btheory. Since the actual nature of time is an empirical matter, in the absence of reasons to suppose that time must, of necessity, be however it is actually, it is natural to conclude that the nature of time is contingent. ${ }^{2}$ For instance, empirically minded philosophers of time often take themselves to have reason, via empirical considerations (particularly considerations arising from the theories of special and general relativity) to suppose that actually the B-theory is true. But such philosophers do not thereby take themselves to have reason to suppose that the B-theory is necessarily true, since absent a priori reasons to hold that the A-theory is necessarily false, there is no reason to suppose that all worlds

\footnotetext{
1 Defenders of "contingentism" about a variety of metaphysical areas include: Cameron (2007), Miller (2010) and Parsons (2006) about composition; Balaguer (1998), Field (2003) and Colyvan (2000; 2001) about mathematical objects; Miller (2009; 2010) and Rosen (2006) more generally about metaphysical theses; and Balaguer (2014) about temporal ontology.

2 Something like these considerations motivate Balaguer's (2014) contingentism about temporal ontology.
} 
are like ours in terms of these empirical features. ${ }^{3}$ Therefore, one cannot simply assume that whichever theory of time is true, is true of necessity: indeed, one apparently has some reason to suppose that any particular theory of time is at best contingently true. In what follows, we argue against this contingentist trend. ${ }^{4}$

We will do this by arguing that temporal facts (unlike many other kinds of facts) are uniquely groundable: however temporal facts are actually grounded, they are necessarily grounded in that way. ${ }^{5}$ It follows that if either the A-theory or the B-theory is actually false, then it is necessarily false. This result focuses the debate between A-theorists and B-theorists on the actual world: whichever side wins there will thereby win in all possible worlds. This raises the prospect of defending modal claims about time on the basis of contingent facts, and exposes such claims to empirical science.

The paper proceeds as follows. In Section 2, we show that the debate between the Atheory and the B-theory is, in part, a debate about how temporal facts are grounded; and we set out some plausible general principles about grounding. In Section 3, we show how, if one endorses these principles, then the sphere of possible worlds in which temporal facts have a grounding structure that is different from their actual grounding structure is much more constrained than expected. In Section 4, we argue that temporal facts are uniquely groundable. In Section 5, we consider the consequences of this for the metaphysics of time.

\section{Grounding, the A-theory, and the B-theory}

In this section we will set out a few assumptions and definitions related to grounding to which we will later appeal, and then argue that the A-theorist and the B-theorist are best seen as disagreeing about (among other things) how temporal facts are grounded. We will then draw some conclusions about the ways in which the grounds of time can vary across worlds, on the assumption that these grounding principles are true.

\subsection{Grounding}

Metaphysics is concerned not only with what exists, but also with what is more fundamental that what. ${ }^{6}$ We will represent fundamentality using a two-place grounding relation, which we take to be irreflexive, asymmetric and transitive. We further assume that the relata of the grounding relation are facts. ${ }^{7}$ To represent this, we adopt the usual

\footnotetext{
3 See for instance Mozersky (2000) and Wüthrich (2011)).

4 Although we do not attempt, here, to respond to Balaguer (2014), we think that what we say in this paper can provide some resources to respond to his argument for contingentism about temporal ontology, by showing in virtue of what certain conditionals are, if true, necessarily true: to wit, they are made true by $a$ priori principles of ground, plus a priori truths about what sort of thing "time" can refer to, plus empirical facts about time's actual structured ground.

${ }^{5} \mathrm{We}$ are also committed to the stronger claim that however time is grounded in any world, necessarily, it is grounded that way. But, as we will see throughout the paper, there is good reason to emphasize the role of the actual world, and it is the thesis as just articulated that we defend.

6 Here we largely follow Schaffer (2009, pp. 375-6). Throughout the paper we will give formal statements in footnotes, for interested readers; others can ignore these and follow the main text.

7 Thus we assume that grounding claims consist of a relational predicate like 'is grounded in' flanked by names for two distinct facts (e.g., 'The fact that $p$ is grounded in the fact that $q$ '). Nothing we say, however, hangs on this way of regimenting grounding claims. One could equally hold that grounding claims should be expressed using a sentential operator flanked by two sentences, such as 'The singleton set \{Socrates\}
} 
convention according to which $[\mathrm{x}]$ is to be read as the fact that $\mathrm{x}$. Canonical grounding claims thereby take the form: $[\mathrm{x}]$ grounds $[\mathrm{y}]$ in world w. ${ }^{8}$ Grounding is partial and relative: a fact may have multiple grounds; and a fact's grounds may in turn be grounded by other facts. If $[\mathrm{x}]$ obtains in $\mathrm{w}$ and has no grounds in $\mathrm{w}$, call $[\mathrm{x}]$ fundamental in $\mathrm{w}$. If $[\mathrm{x}]$ obtains in $\mathrm{w}$ and has grounds in $\mathrm{w}$, call $[\mathrm{x}]$ derivative in $\mathrm{w}$.

For each $[\mathrm{x}]$ in $\mathrm{w}$, define the total ground of $[\mathrm{x}]$ in $\mathrm{w}$, written $\mathrm{G}([\mathrm{x}], \mathrm{w})$, as the set containing precisely those facts that ground $[\mathrm{x}]$ in w. ${ }^{9}$ For all $[\mathrm{x}]$ in $\mathrm{w}$, define the structured ground of $[\mathrm{x}]$ in $\mathrm{w}$, denoted $\mathrm{S}([\mathrm{x}], \mathrm{w})$, as the ordered pair consisting of, first, $\mathrm{G}([\mathrm{x}], \mathrm{w})$, and second, that part of the grounding relation in $\mathrm{w}$ that specifies all and only the grounding relationships among the total grounds of $[\mathrm{x}]$ in $\mathrm{w} .{ }^{10}$ The total ground of $[\mathrm{x}]$ in $\mathrm{w}$ thus provides the entire list of what grounds $[\mathrm{x}]$ in $\mathrm{w}$; the structured ground of $[\mathrm{x}]$ in $\mathrm{w}$ likewise provides the entire list of what grounds $[\mathrm{x}]$ in $\mathrm{w}$, and also describes the grounding relationships among these facts. Note that $[\mathrm{x}]$ is fundamental in w just in case $\mathrm{G}([\mathrm{x}], \mathrm{w})$ is the empty set, $\varnothing$. In this case, $\mathrm{S}([\mathrm{x}], \mathrm{w})$ is the ordered pair consisting of $\varnothing$ and the empty relation on $\varnothing$.

Here's an example. Consider the fact [chairs exist], which obtains in the actual world,@. The actual total ground of [chairs exist], written G([chairs exist],@), is the set of all facts that actually ground the existence of chairs. This set includes [wood exists], [molecules exist], [atoms exist], and so on. The actual total ground of [chairs exist] is thus simply a set of facts. The actual structured ground of [chairs exist] specifies this same set of facts, and in addition specifies the grounding relationships within that set. For example, as well as saying that both [atoms exist] and [molecules exist] ground [chairs exist], it specifies that [atoms exist] grounds [molecules exists]. A fact's ground provides some detail about how that fact is grounded; that fact's structured ground provides more detail.

Next, say that $[\mathrm{x}]$ underpins $[\mathrm{y}]$ in $\mathrm{w}$ just in case $[\mathrm{x}]$ grounds $[\mathrm{y}]$ in $\mathrm{w}$, and in $\mathrm{w}$, any ground of $[\mathrm{y}]$ other than $[\mathrm{x}]$ either itself grounds $[\mathrm{x}]$, or else is grounded by $[\mathrm{x}] \cdot{ }^{11}$ For example, if (in the actual world) [molecules exist] underpins [chairs exist], then [molecules exist] grounds [chairs exist], and any other fact that grounds [chairs exist] either itself grounds [molecules exist] (for example, [atoms exist]) or is grounded by [molecules exist] (for example, [wood exists]). What's ruled out is that [chairs exist] has some other ground, entirely independent of [molecules exist]. Intuitively, then, if [x] underpins [y], then there is no path through the structured ground of $[\mathrm{y}]$ that does not go through $[\mathrm{x}]$. Indeed, we can think of $[\mathrm{x}]$ as a sort of sufficient condition for the obtaining of $[\mathrm{y}]$, in the following sense: in any world in which $[\mathrm{x}]$ underpins $[\mathrm{y}]$, the existence of $[\mathrm{x}]$ entails the existence of [y]; for once you have [x], you also have all the other grounds of [y], since those grounds are either grounded by $[\mathrm{x}]$, or they ground $[\mathrm{x}]$. Moreover, if $[\mathrm{x}]$ underpins $[\mathrm{y}]$, then there

exists, because Socrates exists'. See for instance Fine (2012) for a defense of this latter view.

${ }^{8}$ Formally, we can write $[\mathrm{x}] \backslash_{\mathrm{w}}[\mathrm{y}]$. We employ a world subscript to the grounding relation in order to allow for the prospect that grounding relationships may vary between worlds.

${ }^{9}$ That is: $\mathrm{G}([\mathrm{x}], \mathrm{w})=\left\{[\mathrm{y}]:[\mathrm{y}] \backslash_{\mathrm{w}}[\mathrm{x}]\right\}$

${ }^{10}$ Let $/ \mathrm{xw}$ denote the grounding relation restricted to $\mathrm{G}([\mathrm{x}], \mathrm{w})$. That is, if we write $\backslash_{\mathrm{w}}$ as the set of ordered pairs $\left\{<[y],[z]>:[y] \backslash_{\mathrm{w}}[\mathrm{z}]\right\}$, then $\backslash_{\mathrm{xw}}$ is the subset of this set given by $\left\{<[\mathrm{y}],[\mathrm{z}]>:[\mathrm{y}] \backslash_{\mathrm{w}}[\mathrm{x}]\right.$ and $[\mathrm{z}] \backslash_{\mathrm{w}}[\mathrm{x}]$ and $\left.[\mathrm{y}] \backslash_{\mathrm{w}}[\mathrm{z}]\right\}$. We then have $\mathrm{S}([\mathrm{x}], \mathrm{w})=<\mathrm{G}([\mathrm{x}], \mathrm{w}), \backslash_{\mathrm{xw}}>$.

${ }^{11}$ Writing $[\mathrm{x}] \downarrow_{\mathrm{w}}[\mathrm{y}]$ to say that $[\mathrm{x}]$ underpins $[\mathrm{y}]$ in $\mathrm{w}$, we have: $[\mathrm{x}] \downarrow_{\mathrm{w}}[\mathrm{y}]$ just in case $\left([\mathrm{x}] \backslash_{\mathrm{w}}[\mathrm{y}] \& \forall \mathrm{z}(([\mathrm{x}] \neq[\mathrm{z}]\right.$ $\left.\left.\left.\&[\mathrm{z}] \backslash_{\mathrm{w}}[\mathrm{y}]\right) \rightarrow\left([\mathrm{x}] \backslash_{\mathrm{w}}[\mathrm{z}] \vee[\mathrm{z}] \backslash_{\mathrm{w}}[\mathrm{x}]\right)\right)\right)$. 
is no grounding overdetermination: there is nothing else that is not grounded by $[\mathrm{x}]$, or which $[\mathrm{x}]$ grounds, that also grounds $[\mathrm{y}] .^{12}$

Say that $[\mathrm{x}]$ is multiply groundable if there are worlds $\mathrm{v}$ and $\mathrm{w}$ such that $[\mathrm{x}]$ obtains both in $\mathrm{v}$ and in $\mathrm{w}$, and $\mathrm{S}([\mathrm{x}], \mathrm{v}) \neq \mathrm{S}([\mathrm{x}], \mathrm{w})$. Thus to be multiply groundable is to exist with different structured grounds in different worlds. A fact can be multiply groundable in two ways: it can have different total grounds in different worlds; or it can have the same total ground in all worlds in which it obtains, but be grounded differently in different worlds, in the sense that its grounds stand in different grounding relationships to one another in different worlds. If a fact is not multiply groundable, say that it is uniquely groundable. Thus $[\mathrm{x}]$ is uniquely groundable if and only if, for all worlds $\mathrm{v}$ and $\mathrm{w}$ such that $[\mathrm{x}]$ obtains both in $\mathrm{v}$ and in $\mathrm{w}$, we have $\mathrm{S}([\mathrm{x}], \mathrm{v})=\mathrm{S}([\mathrm{x}], \mathrm{w})$. A fact is uniquely groundable just in case it has the same structured ground in every world in which it obtains.

We think that some facts are multiply groundable. Facts such as [society is just], [Joe is in pain], [this mushroom is poisonous], and so forth, seem like plausible instances of multiply groundable phenomena. We take it that this is relatively uncontroversial and will not argue for it here. Our aim, in this paper, is to argue that temporal facts are uniquely groundable. (See Section 4.)

We will now state and discuss several grounding principles, that is, principles about ground. The first, G-NEC, is well accepted by defenders of grounding, and we will offer no defence of it. The second, NOF, is more controversial. While we offer a reason to endorse the principle, our aim is not, in this paper, to argue in favour of particular principles of ground. Rather, we want to show what follows from accepting some principles that we (and many others) take to be plausible, and therefore to show what one must deny if one wishes to deny our conclusion.

Our first assumption concerns the extent to which the grounding relationships among facts can vary from world to world. One can divide those who investigate grounding into two broad camps: grounding necessitarians and grounding contingentists. Grounding necessitarians hold that there is a necessitation relation between that which grounds, and that which is grounded. Grounding necessitarianism is often expressed as the view that if $[\mathrm{x}]$ is the total ground of $[\mathrm{y}]$, then $[\mathrm{y}]$ is necessitated by $[\mathrm{x}]$, where $[\mathrm{y}]$ is necessitated by $[\mathrm{x}]$ iff for any possible world in which [x] obtains, [y] obtains. Intuitively, the idea is that since a total ground is, by definition, sufficient, in the relevant world, for the existence of that which it grounds, we should think it is sufficient simpliciter. Clearly, however, something less than the total ground might also be sufficient for the existence of that which is grounded: namely, anything that underpins that grounded entity. Thus we will take grounding necessitarianism to be the view that if $[\mathrm{x}]$ underpins $[\mathrm{y}]$, then necessarily, $[\mathrm{x}$ grounds $[\mathrm{y}]$. Thus we formulate grounding necessitarianism as follows:

G-NEC: If $[\mathrm{x}]$ underpins $[\mathrm{y}]$ in $\mathrm{w}$, then for any world $\mathrm{w}^{*}$, if $[\mathrm{x}]$ obtains in $\mathrm{w}^{*}$, then $[\mathrm{y}]$ obtains in $\mathrm{w}^{*}$ and $[\mathrm{x}]$ grounds $[\mathrm{y}]$ in $\mathrm{w}^{*}$.

\footnotetext{
${ }^{12}$ So, for example, if a disjunctive fact is made true by both disjuncts, and neither disjunct grounds the other, then the disjunction has no underpinning, since this would be a case of grounding overdetermination.
} 
This says: if in some world $[\mathrm{x}]$ underpins $[\mathrm{y}]$, then in any world in which $[\mathrm{x}]$ obtains, $[\mathrm{y}]$ also obtains and is grounded by $[\mathrm{x}]$. This definition commits grounding necessitarians not only to supposing that if $[\mathrm{x}]$ underpins $[\mathrm{y}]$ in $\mathrm{w}$, then for any world, $\mathrm{w}^{*}$, if $[\mathrm{x}]$ obtains in $\mathrm{w}^{*}$ then $[\mathrm{y}]$ obtains in $\mathrm{w}^{*}$, but also to the claim that $[\mathrm{x}]$ grounds $[\mathrm{y}]$ in $\mathrm{w}^{*} .{ }^{13}$

Since necessitarianism is by far the most common view amongst those who accept grounding, we will have nothing to say in its defence. We recognize that those (few) who deny G-NEC will be unmoved by some of what follows.

Having assumed G-NEC, we now introduce a further definition. Say that $[\mathrm{x}]$ is a sufficient ground for $[\mathrm{y}]$ just in case there is a possible world $\mathrm{w}$ such that $[\mathrm{x}]$ underpins $[\mathrm{y}]$ in $\mathrm{w}$. The intuitive idea we are aiming to capture here is as follows. If $[\mathrm{x}]$ is a sufficient ground for $[\mathrm{y}]$, then provided that $[\mathrm{x}]$ obtains, it is guaranteed that $[\mathrm{y}]$ obtains: no further facts beyond $[\mathrm{x}]$ are needed to ground $[\mathrm{y}]$. Note that if $[\mathrm{x}]$ is a sufficient ground for $[\mathrm{y}]$, then it follows that $[\mathrm{x}]$ is a possible underpinning of $[\mathrm{y}]$, but not that $[\mathrm{x}]$ is an actual underpinning of [y]: it may be that in the actual world, some further fact, [z], happens to ground [y], along with $[\mathrm{x}]$, such that $[\mathrm{z}]$ and $[\mathrm{x}]$ jointly over-determine $[\mathrm{y}] \cdot{ }^{14}$ Intuitively, sufficiency entails that $[\mathrm{x}]$ is capable of grounding $[\mathrm{y}]$, all by itself, not that it actually does so. (An analogy: Xavier might be strong enough to lift the cupboard alone, even if he in fact receives help from Zoltan; the relevant question is whether Xavier is capable of lifting the cupboard alone, not whether he in fact does so.) Now, given G-NEC, this intuitive notion of sufficiency is plausibly captured by possible underpinning. For if there is a world $w$ in which $[\mathrm{x}]$ underpins $[\mathrm{y}]$, then G-NEC guarantees that every world in which $[\mathrm{x}]$ obtains is such that $[\mathrm{y}]$ obtains and is grounded by $[\mathrm{x}]$. (In our analogy: every world in which Xavier tries to lift the cupboard, with or without help, he succeeds.) The best explanation for this guarantee is surely that $[\mathrm{x}]$ is sufficient, all by itself, to ground $[\mathrm{y}]$. After all, were $[\mathrm{x}]$ not sufficient, then we'd expect there to be a possible world in which [x] obtains but [y] does not. (In the analogy: if in some worlds Xavier were not strong enough to lift the cupboard by himself, we'd expect there to be worlds in which he attempts to lift the cupboard without help, and fails.) But this is precisely what G-NEC rules out. Thus, given G-NEC, being a sufficient ground amounts to being a possible underpinning. Since we are assuming G-NEC, our definition plausibly captures the target notion of a sufficient ground.

The second principle we call the Necessity Of Fundamentality:

NOF: If [f] is fundamental in world $\mathrm{w}$, then for any world $\mathrm{w}^{*}$ in which [f] obtains, $[\mathrm{f}]$ is fundamental in $\mathrm{w}^{*}$.

NOF says that fundamentality cannot vary from world to world: if a fact is fundamental in some world, then it is fundamental in any word in which it obtains. It follows that if a

\footnotetext{
13 One might contend that grounding necessitarians are only committed to the claim that if $[\mathrm{x}]$ underpins $[\mathrm{y}]$ in $\mathrm{w}$, then for any world, $\mathrm{w}^{*}$, if $[\mathrm{x}]$ obtains in $\mathrm{w}^{*}$ then $[\mathrm{y}]$ obtains in $\mathrm{w}^{*}$. That would leave it open that in $\mathrm{w}^{*}$ either $\mathrm{y}$ underpins $\mathrm{x}$, or $\mathrm{x}$ underpins $\mathrm{y}$, or neither underpins the other, and would also leave it open that $[\mathrm{x}]$ grounds $[\mathrm{y}]$, or $[\mathrm{y}]$ grounds $[\mathrm{x}]$, or that no grounding relation obtains between $[\mathrm{x}]$ and $[\mathrm{y}]$. But that would make it mysterious why we should think that wherever $[\mathrm{x}]$ obtains, $[\mathrm{y}]$ obtains: surely we think this is so because we think that in any world in which $[\mathrm{x}]$ obtains, $[\mathrm{x}]$ grounds $[\mathrm{y}]$.

14 Consider a case of disjunction. In worlds where only one disjunct is true, that disjunct underpins the truth of the disjunction. But in worlds where both disjuncts are true, neither disjunct underpins the truth of the disjunction, because there is, in effect, grounding overdetermination. Nevertheless, each disjunct is a sufficient ground for the truth of the disjunction.
} 
fact is derivative in some world, then it is derivative in any world in which it obtains. There has been very little discussion of the status of NOF in the literature; that seems like a mistake (which we hope to begin to remedy). To reject NOF is to accept that what it is to be fundamental is just to bappen to be a fact upon which everything else rests and which rests upon nothing else. ${ }^{15}$ On this view, being fundamental is an entirely relational matter: it amounts to being located at a particular place in a grounding structure. To endorse NOF is to reject this characterization of fundamentality. One motivation for doing so is the widely held view that grounding relations track relational essences. On such a view, if $[\mathrm{x}]$ grounds $[\mathrm{y}]$, then it is essential to $[\mathrm{x}]$ that $[\mathrm{x}]$ grounds $[\mathrm{y}]$. On this view, part of what it is to be some fundamental fact, [f], is to be such that [f] grounds certain further facts. If that is right, then whenever $[\mathrm{f}]$ obtains, $[\mathrm{f}]$ will be fundamental. Moreover, it is part of the essential nature of derivative facts that they are grounded (though perhaps grounded in different facts in different worlds). It follows that for any derivative fact, [d], [d] is grounded by some further fact in every world in which [d] obtains.

We find NOF plausible, and will henceforth explore the consequences of assuming it. Since there is little discussion of NOF, and there are some good reasons to accept it, it ought to be of interest to see what follows from accepting NOF (alongside other plausible principles).

We can derive two consequences from G-NEC and NOF. First, from G-NEC, we can derive what we call the Necessary Relative Grounding Principle:

NRGP: If $[\mathrm{x}]$ underpins $[\mathrm{y}]$ in $\mathrm{w}$, then there is no $\mathrm{w}^{*}$ such that $[\mathrm{y}]$ underpins $[\mathrm{x}]$ in $\mathrm{w}^{*}$.

This says that the relationship of underpinning cannot be "reversed" across worlds. To see that NRGP follows from G-NEC, suppose that $[\mathrm{x}]$ underpins $[\mathrm{y}]$ in w. By G-NEC, it follows that $[\mathrm{x}]$ grounds $[\mathrm{y}]$ in any world $\mathrm{w}^{*}$ in which $[\mathrm{x}]$ obtains. Since grounding is asymmetric, it follows that $[\mathrm{y}]$ does not ground $[\mathrm{x}]$ any world $\mathrm{w}^{*}$, and so that $[\mathrm{y}]$ does not underpin $[\mathrm{x}]$ in any world $\mathrm{w}^{*}$. Thus we have NRGP.

The second consequence of $\mathrm{NOF}$ and G-NEC is:

FUND: If in the actual world $[\mathrm{f}]$ is fundamental and $[\mathrm{f}]$ underpins $[\mathrm{x}]$, then in every world in which $[\mathrm{f}]$ obtains, $[\mathrm{f}]$ is fundamental and $[\mathrm{f}]$ grounds $[\mathrm{x}]$.

This says that if $[\mathrm{f}]$ is actually fundamental and actually underpins $[\mathrm{x}]$, then $[\mathrm{f}]$ is fundamental and grounds $[\mathrm{x}]$ in every world in which $[\mathrm{f}]$ obtains. To see that FUND follows from NOF and G-NEC, suppose that in the actual world $[\mathrm{f}]$ is fundamental and [f] underpins $[\mathrm{x}]$, and let $\mathrm{w}$ be a world in which [f] obtains. Then by NOF, $[\mathrm{f}]$ is fundamental in w. And by G-NEC, $[\mathrm{x}]$ obtains in $\mathrm{w}$ and $[\mathrm{f}]$ grounds $[\mathrm{x}]$ in $\mathrm{w}$. Thus we have FUND.

Recall that $[\mathrm{x}]$ is multiply groundable just in case there are worlds $\mathrm{v}$ and $\mathrm{w}$ such that $[\mathrm{x}]$ obtains in both $\mathrm{v}$ and $\mathrm{w}$ and $\mathrm{S}([\mathrm{x}], \mathrm{v}) \neq \mathrm{S}([\mathrm{x}], \mathrm{w})$ : that is, just in case there are two worlds in

\footnotetext{
15 Schaffer, for instance, rejects NOF, since he thinks the whole universe is fundamental. Since he thinks there are other worlds in which our universe is a proper part of that universe, he thinks that in that world our universe is derivative (being grounded in the whole universe in that world).
} 
which $[\mathrm{x}]$ obtains such that $[\mathrm{x}]$ has a different structured ground in each world. Now, say that $[\mathrm{x}]$ is multiply underpinnable if there are worlds $\mathrm{v}$ and $\mathrm{w}$ such that $[\mathrm{x}]$ obtains in both $\mathrm{v}$ and $\mathrm{w}$, and in $\mathrm{v},[\mathrm{y}]$ underpins $[\mathrm{x}]$, while in $\mathrm{w},[\mathrm{y}]$ does not underpin $[\mathrm{x}]$. Note that if $[\mathrm{x}]$ is multiply underpinnable, then $[\mathrm{x}]$ is multiply groundable. For if $[\mathrm{x}]$ is underpinned by $[\mathrm{y}]$ in $\mathrm{v}$ and is not underpinned by [y] in $\mathrm{w}$, this must be because either (i) [y] grounds [x] in $\mathrm{v}$ but not in $\mathrm{w}$, in which case $[\mathrm{x}]$ has a different structured ground in $\mathrm{v}$ than it does in $\mathrm{w}$, or (ii) $[\mathrm{y}]$ grounds $[\mathrm{x}]$ in $\mathrm{v}$ and $\mathrm{w}$, but $[\mathrm{y}]$ does not underpin $[\mathrm{x}]$ in $\mathrm{w}$ because in $\mathrm{w}$ there is a further independent ground of $[\mathrm{x}]$, in which case $[\mathrm{x}]$ has a different structured ground in $\mathrm{v}$ than it does in $\mathrm{w}$. The converse does not hold. That is, $[\mathrm{x}]$ may be multiply groundable without being multiply underpinnable. For $[\mathrm{x}]$ may have a different structured ground in $\mathrm{v}$ and $\mathrm{w}$, but have the same (unstructured) grounds in $\mathrm{v}$ and $\mathrm{w}$. If $[\mathrm{x}]$ has the same unstructured ground in all worlds, then it will have the same underpinnings in all those worlds even though its structured ground varies across worlds. Our intention, in Section 3 , is to argue that some facts, in particular, temporal facts, are neither multiply groundable nor multiply underpinnable. To show this we only need to show that temporal facts are not multiply groundable, since this entails that they are not multiply underpinnable. This means denying the following:

SMGT: For any $[\mathrm{x}]$ such that $[\mathrm{x}]$ is derivative and $[\mathrm{x}]$ obtains at more than one world, there are worlds $\mathrm{v}$ and $\mathrm{w}$ such that $\mathrm{S}([\mathrm{x}], \mathrm{v}) \neq \mathrm{S}([\mathrm{x}], \mathrm{w})$.

The Strong Multiple Groundability Thesis (SMGT) says that every fact that is derivative in some world (and thus if NOF is true, derivative in every world) is such that it has different structured grounds in different worlds. ${ }^{16}$ Our aim in Section 3 is to show that there are some facts, namely temporal facts, that are uniquely groundable (and therefore uniquely underpinnable), and therefore that SMGT is false.

\subsection{The A-theory and the B-theory}

We take the A-theorist and the B-theorist to make competing claims about how temporal facts are grounded. According to B-theorists, there exists no A-series that is not reducible to B-relations (relations of earlier than, later than, and simultaneous with) and indexical facts. Thus talk about past, present, and future is really talk about where one is located (the present), about events earlier than one's location (past events), and about events later than one's location (future events). By contrast, A-theorists hold that the temporal series consists in an order of events in terms of the monadic A-properties of being past, present, and future. ${ }^{17}$ According to the A-theorist, B-relations are reducible to

16 Compare this to the Weak Multiple Groundability Thesis (WMGT):

WMGT: For some $[\mathrm{x}]$ such that $\mathrm{x}$ is derivative and $[\mathrm{x}]$ obtains at multiple worlds, there are worlds $\mathrm{v}$ and $w$ such that $S([x], v) \neq S([x], w)$

WMGT says that there is at least something that is multiply groundable. We accept WMGT but will not argue for it here.

${ }_{17}$ Not every A-theorist might be happy with this characterization. For instance, some presentists either deny that there are properties of pastness and futurity, or deny that there are properties of pastness, presentness, or futurity (instead, there is just existence). We do not think it obvious that presentists need to deny the existence of said A-properties, and so think that we can adequately capture a presentist view. For instance, it is no part of our framework that such properties must be primitive or fundamental, and we see no reason why a presentist should deny there are such properties thus understood. However, presentists who do deny there are such properties will not find this framework amenable. 
these monadic A-properties. Thus A- and B-theorists make opposing claims about ontological priority: they disagree about what is the more fundamental ground of time.

We will suppose that for each A-property instantiated by a certain set of objects and events, there exists a corresponding fact. Thus, for instance, for any object or event that has the property of being present, there is an A-fact, which is the fact that that object or event has the property of being present. Likewise, for any object or event that has the property of being past (or future), there is an A-fact, which is the fact that that object or event has the property in question. We call the complete set of these facts the A-facts. In addition, we will suppose that for every B-relation that obtains between two relata, there is a B-fact that corresponds to the obtaining of that relation. Thus for any pair of objects or events, $\mathrm{E}$ and $\mathrm{E}^{*}$, if $\mathrm{E}$ bears the relation of being earlier-than (or, respectively, laterthan, or simultaneous-with) $\mathrm{E}^{*}$, then there is a $\mathrm{B}$-fact which is the fact that $\mathrm{E}$ bears the relation of being earlier-than (or, respectively, later-than, or simultaneous-with) to $\mathrm{E}^{*}$. We call the complete set of these facts the B-facts. Roughly speaking, then, the A-theorist thinks that the A-facts ground the B-facts. The B-theorist thinks the reverse is true.

Say that $w$ is A-theoretic iff: (1) temporal facts obtain in $w{ }^{18}$ (2) A-facts obtain in w and ground the temporal facts in w; and (3) if any B-facts obtain in w, then either the A-facts ground the $\mathrm{B}$-facts in $\mathrm{w}$, or the $\mathrm{B}$-facts are not a sufficient ground for the $\mathrm{A}$-facts.

Say that w is B-theoretic iff: (i) temporal facts obtain in w; (ii) B-facts obtain in w and ground the temporal facts in $\mathrm{w}$; and (iii) if A-facts obtain in $\mathrm{w}$, then the B-facts ground the A-facts in w, and the B-facts are a sufficient ground for the A-facts.

Some care is needed here. When the A-theorist says that B-facts are grounded by A-facts, she takes the A-facts in question to involve monadic A-properties. When the B-theorist says that A-facts are grounded by B-facts, she supposes that the A-facts do not include monadic properties. For this reason, it is common to refer to the A-properties posited by the A-theorist as irreducible A-properties, and those posited by the B-theorist as reducible A-properties. We think this is misleading: while the A-theorist is committed to the existence of A-properties that do not reduce to B-relations, she need not be committed to the existence of A-properties that are irreducible simpliciter. ${ }^{19}$

Consider Figure 1. In w1, the A-facts underpin both the B-facts and the temporal facts, and the B-facts underpin the temporal facts. Our definitions classify this world as Atheoretic, as is intuitively correct. In w2, the B-facts underpin both the A-facts and the temporal facts, and the A-facts underpin the temporal facts. Our definitions classify this world as B-theoretic, again correctly. In w3, both the B-facts and something else, X, ground the A-facts, and the A-facts underpin the temporal facts while the B-facts do not (though the B-facts do ground the temporal facts). On our definitions, how w3 is classified depends on whether or not the B-facts are a sufficient ground for the A-facts. This in turn depends on whether there is a possible world in which the B-facts underpin

\footnotetext{
18 Here, we suppose that temporal facts obtain in w iff w contains time.

19 Notice that given our characterization, some recent versions of presentism that are purportedly not Atheoretic turn out to be so. On views such as those of Tallant (2012) and Rasmussen (2015), times are abstract objects (all of which exist) related by primitive B-relations, but only one of which obtains (or is true), and which one obtains, changes. On this view the B-relations are primitive (and not grounded in any A-facts). On the assumption, however, that the property of being present is an A-fact, on our taxonomy this is still a version of the A-theory. For there are A-facts (like being present) that are not underpinned (or grounded) by the B-relations.
} 
the A-facts: if w2 is possible, then the B-facts are a sufficient ground for the A-facts, and w3 counts as B-theoretic; if no world like w2 is possible, then the B-facts are not a sufficient ground for the A-facts, and w3 counts as A-theoretic. In the former case, X is not doing any heavy lifting in w3, and the B-facts alone are enough to deliver the A-facts and the temporal facts; so it's intuitively correct to count w3 as B-theoretic. In the latter case, $\mathrm{X}$ is playing a crucial role in grounding the A-facts and the temporal facts in w3, and so w3 is intuitively not B-theoretic.

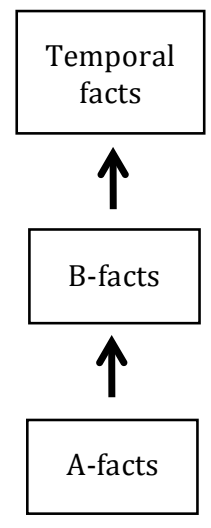

w1

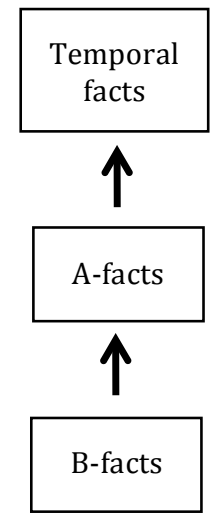

w2

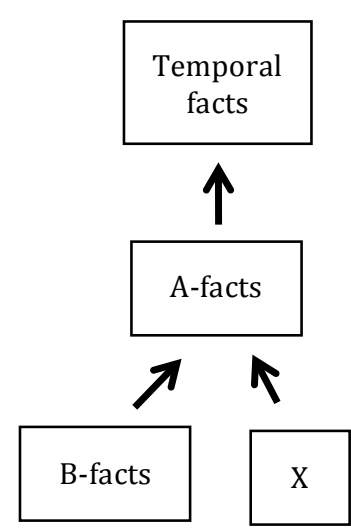

w3

\section{FIGURE 1.}

Our definitions leave it open that (either version of) the A-theory or the B-theory is contingently true. For all the definitions say, some worlds may be A-theoretic and others B-theoretic. Call this view contingentism, and its negation necessitarianism. Necessitarianism is thus the view that either the A-theory or the B-theory (or both) is necessarily false.

\section{Necessitarianism and the unique groundability of time}

Are there reasons for supposing time to be uniquely groundable that arise from the grounding principles we listed earlier? In this section, we show that although these principles do not entail that temporal facts are uniquely groundable unless temporal facts are actually fundamental, they do entail that there are far fewer possible structured grounds of the temporal facts that one might have expected.

One can partition epistemic possibility space into cases in which the temporal facts are actually fundamental, and cases in which they are actually derivative. Suppose the temporal facts are actually fundamental. According to NOF, it follows that in any world in which time exists, the temporal facts are fundamental. Consequently in all worlds with temporal facts, the structured ground of those facts is the ordered pair consisting of the empty set $\varnothing$ and the empty relation on $\varnothing$. So temporal facts are (trivially) uniquely groundable.

But now suppose that the temporal facts are actually derivative. Then nothing follows from our grounding principles regarding whether temporal facts are uniquely or multiply groundable. This is a good thing, since if the unique groundability of temporal facts followed from perfectly general principles, that could only be because every derivative fact 
is uniquely groundable. This would be far too strong. If temporal facts are uniquely groundable, then this must be in virtue of some specific features of time itself.

Having said that, learning about the actual structured ground of the temporal facts does tell us a variety of things about the possible structured grounds of the temporal facts, conditional on our grounding principles being true. Suppose that actually the A-facts are fundamental, and these underpin the B-facts, which underpin the temporal facts. (See w1 in Figure 1.) Then we know some things about the possible structured grounds of time. We know that in any world with A-facts, those facts are fundamental (by NOF); and that they ground the B-facts facts in all such worlds (by G-NEC). Further, we know that there are no worlds in which B-facts are fundamental (by NOF) and no worlds in which B-facts underpin A-facts (by NRGP). It follows that in any worlds in which there are Afacts, those A-facts are a sufficient ground for both the A-facts and the B-facts. Given our definitions, it follows that any world containing A-facts is an A-theoretic world.

Alternatively, suppose that the actual world is one in which the B-facts are fundamental and underpin the A-facts, which in turn underpin the temporal facts. (See w2 in Figure 1.) Then the A-facts are, necessarily, derivative (by NOF); and in any world with B-facts, the B-facts ground the A-facts (by G-NEC); and in no world with A-facts do these ground the B-facts (by NRGP). So in any world with B-facts, the B-facts are a sufficient ground for the A-facts, and for the temporal facts. So, by our definitions, any world containing B-facts is a B-theoretic world.

What if neither A-facts nor B-facts are fundamental? One might think this leaves open the possibility that there exists a pair of worlds, $\mathrm{w}$ and $\mathrm{w}^{*}$ such that in $\mathrm{w},[\mathrm{x}]$ underpins the A-facts, which underpin the B-facts, which underpin the temporal facts; and in $\mathrm{w}^{*}$, [y] underpins the B-facts, which underpin the A-facts, which underpin the temporal facts. If so, then the temporal facts are ultimately grounded by two different things: $[\mathrm{x}]$ in one world, and $[y]$ in the other. Not so. One of these worlds is impossible if NRGP holds. If A-facts underpin B-facts in w, then by NRGP there is no world in which Bfacts underpin A-facts. Thus if $\mathrm{w}$ is possible then $\mathrm{w}^{*}$ is not.

Given the grounding principles we have outlined, if A-facts and B-facts are both derivative, then they are of necessity derivative, and it is possible that they are differently grounded in different worlds. But whatever the relative whole grounding relations between A-facts and B-facts are actually, that relativity of grounds will hold across all worlds (by NRGP). Thus although there may be worlds where the temporal facts have a different structured ground, the various grounding principles significantly constrain the ways in which the structure of this ground can vary across worlds.

Nevertheless, this does not show that the temporal facts are uniquely groundable. It leaves open the possibility that there are worlds in which A-facts do not underpin B-facts and worlds in which B-facts do not underpin A-facts. If such worlds are possible then there will be a pair of worlds $\mathrm{w}$ and $\mathrm{w}^{*}$ such that in $\mathrm{w},[\mathrm{x}]$ underpins the A-facts, and the A-facts ground, but do not underpin, the B-facts, and the B-facts underpin the temporal facts; and in $\mathrm{w}^{*},[\mathrm{y}]$ underpins the B-facts, and the B-facts ground, but do not underpin, the A-facts, and the A-facts underpin the temporal facts. Nothing in our grounding principles rules out the existence of $\mathrm{w}$ and $\mathrm{w}^{*}$. But $\mathrm{w}$ and $\mathrm{w}^{*}$ are worlds in which the temporal facts have different structured grounds.

\section{Defending Necessitarianism}


In this section we defend necessitarianism: the view that either the A-theory or the Btheory is necessarily false. We do this by arguing that temporal facts are uniquely groundable. Recall: $[\mathrm{x}]$ is uniquely groundable if and only if $[\mathrm{x}]$ has the same structured ground in all worlds in which $[\mathrm{x}]$ obtains. We will defend the unique groundability of temporal facts by arguing that such facts are necessarily grounded in whatever way they are grounded in the actual world. From unique groundability, necessitarianism follows. To see this, note that contingentism entails that temporal facts are multiply groundable: if contingentism is true, then there is an A-theoretic world, w, and a B-theoretic world, w*; and since the A-theory and the B-theory are incompatible claims about the structured ground of temporal facts, it follows that the temporal facts have different structured grounds in w and $\mathrm{w}^{*}$; and so those facts are multiply groundable. Since contingentism entails that the temporal facts are multiply groundable, unique groundability entails necessitarianism. Therefore, to defend necessitarianism it suffices to show that the temporal facts are uniquely groundable.

We now give two reasons for accepting the unique groundability of the temporal facts.

\subsection{Obstacles to defining time functionally}

One reason for accepting the unique groundability of the temporal facts is that we lack one of the usual reasons for taking facts to be multiply groundable. Consider why one might think that some fact $[\mathrm{x}]$ is multiply groundable. Typically, we find such a claim plausible when what it is to be a kind of object, or type of substance, which in turn is a constituent of a fact such as $[\mathrm{x}]$, is to be something that plays a certain functional role. For example, why think (some) facts involving mental states are multiply groundable? Because we think that what it is to be a mental state is to play a certain role in something's overall mental economy, and that what it is to be a particular mental state is to a play a particular functional role in that economy. Moreover, we think that different sorts of things could play that functional role.

Some, like Mark Johnston, ${ }^{20}$ think water is like this (though of course this is not the orthodox view). Thus Johnston thinks that in our world the fact that there is water is grounded by the fact that there is $\mathrm{H}_{2} \mathrm{O}$, while in other worlds this fact is grounded by something else - say the fact that there is XYZ, where XYZ is a potable clear liquid. The reason to think that the fact that there is water is multiply groundable is precisely that one thinks that water is a functional kind, and that something is water just in case it plays a particular functional role.

Recall that we are supposing that there is time in a world iff there are temporal facts in that world. Thus, we think, the principal reason to think that the temporal facts are multiply groundable is if one thinks that time ought to be defined functionally.

We do not take ourselves to be able to show that time cannot be defined functionally. Rather, in what follows, we offer some reasons to be sceptical that there is an adequate functional definition of time. Thus we aim to shift the burden of proof onto the defender of the view that temporal facts can have different structured grounds in

${ }^{20}$ Johnston (1997) 
different worlds: those claiming that this is possible owe us a functional account of the nature of time that permits time to be multiply realisable.

One reason to be sceptical that time ought be defined functionally is that it is unclear what the functional role of time could be. ${ }^{21}$ Time does not seem to be relevantly like water (if you think Johnston is right about water) or the desire for ice cream. Baron and Miller (2015) note that one obstacle to providing a functional characterisation of time is that it is difficult to avoid characterisations that are either obviously too inclusive, or obviously not inclusive enough. For instance, one might pick out a very general highlevel role: one might say that time is whatever is discoverable by the physical sciences and partially orders events into a metrical structure. But plausibly, any such account will be too permissive: any number of relations that are most definitely not temporal can be used to partially order events and yield a metrical structure. On the other hand, strategies that build more into the characterisation of time quickly become too exclusive. If we build in more physical constraints, say by talking about the specific roles of time in various physical theories, then we risk it turning out that there is actually no time (if those physical theories are false), or that there is only time in worlds very physically similar to ours. Furthermore, if we say that time is whatever is discoverable by science and partially orders moments into a metrical structure of earlier-than and later-than relations, then we prejudge matters in favour of the B-theorist; and it is, at any rate, no longer obvious that we are offering a functionalist account of time. Moreover, the resulting characterisation is arguably not permissive enough: it will result in concluding that actually there is no time if there are only C-relations but no B-relations as some (for instance Huw Price) contend. ${ }^{22}$

We cannot show that there is no way to define time functionally along something like these lines. However, since it is far from obvious how such a definition would work, we think there is good reason to be sceptical, at least until a functionalist about time offers us a promising story. We thus take the burden of proof to lie with the functionalist here. The only functionalist story that has been advanced in any detail comes from Baron and Miller (2015). Their suggestion is that we define the time role in terms of the effects that time has on creatures like us: time is whatever physical phenomenon is discoverable by the physical sciences and is responsible for our temporal phenomenology. (Roughly, our temporal phenomenology is our partitioning the world into ordered moments, our experiencing them in said order, our experiencing the present with a certain vividness, and our having differential attitudes towards events that are partitioned as being in the past as opposed to future. This is analogous to (partly) defining water in terms of it being clear and potable: water is only clear and potable relative to our particular visual and gastronomic systems.) If this proposal succeeds, contingentism will look more plausible. Let us now assess the proposal.

We begin by drawing a distinction. If time is functionally characterised, then in order to establish whether or not temporal facts are multiply groundable, we must specify how to use the functional role of time in order to determine what our term 'time' picks out in non-actual worlds. Only then can we settle whether or not, given what 'time' picks out,

\footnotetext{
21 Perhaps there are multiple concepts of time deployed by different individuals, or different disciplines (perhaps there is a distinctly "physical" concept deployed in classical physics). For our purposes we are assuming that whatever concept of time and temporal facts is at issue, it is the one that metaphysicians of time deploy in their discussion of time. We assume that this is a shared concept (even if perhaps there are somewhat different conceptions of that concept).

22 Price (1996).
} 
the temporal facts in any given non-actual world are differently grounded to the actual temporal facts. There are two well-known strategies here. The first: in any given world, 'time' picks out whatever plays the time role in that world. (This is analogous to a common view of mental state terms like 'pain'. ${ }^{23}$ ) Call this the non-rigidifying strategy. The second strategy is to take the time role and rigidify: in any given world, 'time' refers to whatever plays the time role in the actual world. (This is analogous to a common view of natural kind terms like 'water'. ${ }^{24}$ ) Call this the rigidifying strategy. We will assess the aforementioned functionalist proposal relative to each of these strategies.

First, suppose that one accepts something like the Baron and Miller proposal, and endorses the non-rigidifying strategy. The non-rigidifying strategy requires us to determine, for each possible world, w, what (if anything) plays the time role in w. On the Baron and Miller proposal, this means determining what is responsible for the temporal phenomenology in w. But how are we to determine which phenomenology in w counts as temporal phenomenology ${ }^{25}$ One option is to characterise the temporal phenomenology in $\mathrm{w}$ as the phenomenology for which time is responsible in $\mathrm{w}$. But that option is unavailable here, since it will lead to a vicious circle: we are trying to pick out time in w by picking out the temporal phenomenology in w, so we cannot pick out the temporal phenomenology in w by picking out time in w. Instead, one might try to characterise the temporal phenomenology in w by piggy-backing on our actual temporal phenomenology. For example, one might say that the temporal phenomenology in $\mathrm{w}$ is whatever phenomenology of this kind occurs in $\mathrm{w}$, where the demonstrative is cashed out via a careful account of our actual temporal phenomenology. But this route is unpromising, for the following reason. Consider two counterfactual worlds, w and $\mathrm{w}^{*}$. Now, one may have firm intuitions about whether there is time in $\mathrm{w}$ and/or $\mathrm{w}^{*}$, or one may be unsure whether or not there is time in one or both worlds. But regardless, one does not need to know what kind of phenomenology obtains in those worlds in order to have a view about whether or not there is time in those worlds. Indeed, whether or not there is time in those worlds does not seem to be sensitive to the nature of the phenomenology in those worlds. If the only difference between $\mathrm{w}$ and $\mathrm{w}^{*}$ were the nature of the phenomenology in those worlds, then it would seem implausible indeed that one contains time and the other does not. But if that is right, then an appeal to phenomenology is not the right way to proceed. We conclude that there is currently no viable way to define time functionally via the non-rigidifying strategy. Until such an account is forthcoming, we thus have good reason to reject the idea that time can be characterised in this way.

Let us, then, turn to the rigidifying strategy. Recall the central idea: in world w, 'time' picks out whatever plays the time role in the actual world. This strategy promises to overcome the deficiencies of the rigidifying strategy: it merely requires us to determine

\footnotetext{
23 On this view, 'pain' refers in any given world to whatever states play the pain role in that world. Functionalists about mental states often have this view, or the nearby view that 'pain' refers, in any world, to the second-order state of having something play the pain role in that world. See for instance Lewis (1966) for an early statement of the view and Braddon-Mitchell and Jackson (1999); Phelan and Buckwalter (2012) for more recent ones. Thus creatures in other worlds can be in pain, even if their brains are radically different to ours.

$24 \mathrm{On}$ this view, 'water' refers in any given world to whatever actually plays the water role, namely $\mathrm{H}_{2} \mathrm{O}$. Thus $\mathrm{H}_{2} \mathrm{O}$ in another world is water, even if it doesn't play the water role in that world. Among those subscribe to this view of natural kinds are (Braddon-Mitchell (2004a); (2004b); (2009); Chalmers (2004); Jackson (1998); (2004); (2007); (2009) and Beebee and Sabbarton-Leary (2010).

25 The worry we identify here bears some similarity to that noted in Stroud (2000; p. 160) in the context of perceptions of colour.
} 
what time is actually, via the relevant functional role, and then conclude that time is, necessarily, that phenomenon. ${ }^{26}$

One might suspect that the rigidifying strategy simply delivers the result that temporal facts are uniquely groundable. That is, one might suspect that what it is to discover that time is the same thing in every world is to discover that the temporal facts have the same grounds in every world. But that cannot be right. What we discover here is an identity: we discover that time $=\mathrm{X}$, where $\mathrm{X}$ is whatever actually plays the time role. We thus discover an identity relation between the temporal facts and some other set of facts. Since identity is not a grounding relation, we don't discover anything about grounds. Moreover, discovering that some temporal fact is identical to some particular fact $[\mathrm{x}]$ in every world doesn't preclude it being the case that $[\mathrm{x}]$ has different grounds in different worlds. Once we discover that the fact in question is identical to [x], we must still ask whether $[\mathrm{x}]$ is uniquely grounded. We think there is reason to think that it is.

Here is why. The rigidifying strategy is typically associated with natural kinds and proper names. 'Time' is not a proper name. But it is plausible that it is a natural kind term if, as we have just argued, it is not a functional term. Here is a plausible principle regarding natural kinds:

NK: If ' $T$ ' is a natural kind term then the actual structured ground of [T exists], is, necessarily, the structured ground of [T exists].

Should NK be accepted? Consider the case of water. The orthodox view is that 'water' is a natural kind term. The thought is that, when we discover the chemical composition of water, we discover its essence: we discover that being $\mathrm{H}_{2} \mathrm{O}$ is its essence. Now, importantly, it does not immediately follow that $\left[\mathrm{H}_{2} \mathrm{O}\right.$ exists] itself is not multiply grounded. For example, one might try to argue that ' $\mathrm{H}_{2} \mathrm{O}$ ' is a functional expression (even if 'water' is not), and so that some fact that underpins $\left[\mathrm{H}_{2} \mathrm{O}\right.$ exists], say [y], is multiply groundable. For instance, one might claim that $\left[\mathrm{H}_{2} \mathrm{O}\right.$ exists $]$ is grounded in [particles of a certain kind exist and are arranged in a certain way]; and one might also claim that this latter fact is multiply groundable-perhaps it is grounded in, say, [vibrating strings exist] in one world, and [computational facts exist] in some other world. If this view is correct, then NK is false.

W think that this view is ultimately mistaken. While it is epistemically open that $\left[\mathrm{H}_{2} \mathrm{O}\right.$ exists] is ultimately grounded in [vibrating strings exist], or ultimately grounded in [computational facts exist], we are inclined to think that whatever is actually the ultimate ground of $\left[\mathrm{H}_{2} \mathrm{O}\right.$ exists] is necessarily the ultimate ground of $\left[\mathrm{H}_{2} \mathrm{O}\right.$ exists]. We think it implausible, for example, that if actually $\left[\mathrm{H}_{2} \mathrm{O}\right.$ exists] is ultimately grounded by [vibrating strings exists], that possibly $\left[\mathrm{H}_{2} \mathrm{O}\right.$ exists] is ultimately grounded in [computational facts exist]. At least, we think this is implausible insofar as it is plausible that water is $\mathrm{H}_{2} \mathrm{O}$ and necessarily so. The principle here is this: facts about natural kinds do not obtain at higher levels, only to be grounded by lower-level facts that are themselves multiply groundable. To be sure, there are worlds in which there exists some stuff-call it XYZ- that is not water, but is superficially very similar to water. In such worlds, [XYZ exists] may well have a different structured ground to the actual structured ground of $\left[\mathrm{H}_{2} \mathrm{O}\right.$ exists]. But

26 One might think this is somewhat like the case of water if one thinks that the functional characterization of water as the potable clear stuff in the lakes provides a way to figure out where the water is, and then empirical testing tells us what that stuff is. Then water is, necessarily, whatever the actually potable clear stuff in the lakes is. 
this does not show that $\left[\mathrm{H}_{2} \mathrm{O}\right.$ exists] has different structured grounds in different worlds, since $\left[\mathrm{H}_{2} \mathrm{O}\right.$ exists] does not obtain in these XYZ-worlds. We think that what it is to discover that ' $\mathrm{T}$ ' is a natural kind term is to discover that ' $\mathrm{T}$ ' picks out something such that [ $\mathrm{T}$ exists] has the very same structured grounds in every world; not merely that ' $\mathrm{T}$ ' picks out something such that [ $\mathrm{T}$ exists] has the same ground in every world, where that ground, in turn, might be differently grounded across worlds. For this reason, we endorse NK.

If one endorses NK, then one has good reason to think that if the rigidifying strategy is right for 'time', then temporal facts have the same structured ground in every world that they have actually. In that case, temporal facts are uniquely groundable, and necessitarianism is vindicated.

But suppose that one does not find NK plausible. Then, so far, we have only shown that time is, of necessity, whatever actually plays the time role. But if NK is false, then for all we have said so far, it could be that whatever actually plays the time role, call it TIME, is such that [TIME exists] is multiply groundable. In that case, it could be that the temporal facts are multiply groundable, contrary to necessitarianism.

We think there are independent reasons to rule this possibility out. Suppose we discover that time is TIME (and necessarily so), since TIME is what actually plays the time role. Then [TIME exists] iff [temporal facts exist]. Now, if [TIME exists] is multiply groundable, then there is a world, $w^{*}$, in which [TIME exists] has a different structured ground to its actual structured ground. Moreover, in some world $w^{* *}$, TIME does not play the time role (just as in some world, $\mathrm{H}_{2} \mathrm{O}$ does not play the water role). Given that these two factors vary independently, there will be still another world, $\mathrm{w}^{* * *}$, in which [TIME exists] has a different structured ground to the one it has actually and in which TIME plays a different role to the one it plays actually. According to the view under consideration, since TIME is, necessarily, time, world $\mathrm{w}^{* * *}$ is one in which there is time. But we do not see why we should think that TIME is time in $\mathrm{w}^{* * *}$. We might be inclined to think TIME is time if it shared the same structured ground as TIME in our world, just as we are inclined to say that $\mathrm{H}_{2} \mathrm{O}$ is water in worlds in which it shares the same structured ground as actual $\mathrm{H}_{2} \mathrm{O}$, even if in those worlds it does not play the water role. Furthermore, we might be inclined to think that TIME is time if, despite not having the same structured ground as it does actually, it plays the functional role of time in that world. But in $\mathrm{w}^{* * *}$, TIME does neither of these things. We are thus sceptical that there is good reason to accept that TIME is time. So, we think, there is good reason to accept that if time is, necessarily, whatever plays the time role, then whatever actually plays the time role, TIME, must be such that [TIME exists] has the same structured ground in every world. For it is in virtue of having the same structured ground in every world that we can legitimately identity what actually plays the time role (TIME) as time, across worlds in which TIME fails to play the time role. If correct, this vindicates necessitarianism.

Let us make one final point. Arguably, not all cases of multiply groundability are the result of some phenomenon being functionally defined. One might think, for instance, that [pain exists] is multiply groundable, but that pain is not defined by its functional role. For instance, one might think that pain is an experience with a phenomenal character like this, where 'this' is a demonstrative that points to an experience with a particular phenomenal character. If we call this phenomenal character $\mathrm{P}$, then pain is whatever experience has P. On this view, [pain exists] might well be multiply groundable. 
Applied to the case of time, however, matters are not so straightforward. Time is not an experience. We could say that time is whatever is responsible for those of our experiences with a certain phenomenal character; but that just brings us back to a strategy we have already considered, since, in effect, it defines time functionally. The other option is to say that time is that thing, where that thing is a demonstrative. Then, so long as that thing is multiply groundable, the temporal facts are multiply groundable. The problem is that we cannot point to time, in even the figurative sense in which can point at an experience of pain. To get a handle on what we would be pointing to, we would need some sort of functional definition to get the process off the ground (namely, I'm pointing at the thing that does these things). Therefore, even if non-functional accounts can sometimes give rise to multiple groundability, this is not plausibly the case for temporal facts.

\subsection{Actuality bias}

Another reason to accept the unique groundability of temporal facts is that it neatly accommodates what we might call an "actuality bias" in folk judgments about the nature of time. There is some empirical evidence that, with respect to a range of cases, the folk show an actuality bias. We think it plausible that the same bias extends to the case of time. ${ }^{27}$ We think that there are certain features, F, such that: (i) should the folk discover that the actual world has F, they would judge F to be necessary for time in other, nonactual worlds; but (ii) were the folk to discover that the actual world lacks F, they would nevertheless judge that the actual world contains time. For example, one candidate for $F$ is the feature of containing an objectively present moment. Were the folk to discover that the actual world does contain an objectively present moment, we think, they would regard this as a necessary condition for time, thereby concluding that any world without an objectively present moment is one without time. On the other hand, were they to discover that the actual world does not contain an objectively present moment, but merely relations of earlier and later than, then they wouldn't judge that there is actually no time. Rather, they would relax their standards, concluding that relations of earlier and later than are sufficient for time (and necessarily so).

\footnotetext{
27 This is a piece of empirical speculation. A study that tests it is currently underway. Having said that, we do have data about a range of responses that subjects (non-philosophers) have to other cases that are relevantly similar. (This data is currently unpublished, but can be made available.) For instance, we have data about what those who think there is actually libertarian free will are inclined to say if we ask them to suppose that we discover that actually, indeterminism is false. (Namely, we have data about whether they are inclined to become error theorists about free will.) We also have data about what folk who are dualists are inclined to say when we ask them to suppose that they discover that actually, there are no dualistic conscious states.

In both cases we find that folk are fairly disinclined to become error theorists, and are inclined instead to alter what they take to be necessary for existence of free will or consciousness. At present, the number of those who fail to become error theorists is just over $50 \%$. However, the data suggests that this might in part be an effect of some subjects being unable to imagine the case in which they discover that actually, the world is different from how they do (in fact) take it to be. In order to test this, we currently have a study underway in which subjects are trained up in being able to imagine that the actual world is different to how they suppose it to be. Our hypothesis is that amongst subjects able to do this, the proportion of subjects who become error theorist will be significantly less than $40 \%$. We also think that, when the data comes in on subjects with regard to their views about time, subjects who have passed the training phase will, by and large, tend not to become error theorists. However, this data is not yet ready and so the above claim is, at this stage, empirical speculation.
} 
The unique groundability of temporal facts delivers these judgments. Why should that be a good thing? We take it that, other things being equal, it is better if one's metaphysical theory accommodates sufficiently robust folk judgements made after reflection. So that is a weak reason to prefer the view that temporal facts are uniquely groundable over the view that they are not. A better reason is that folk concepts play an important subject setting role: they tell us how the world would need to be, in order for a concept to be satisfied. Even if (as is no doubt the case) there are more fine-grained concepts of time found in the physical sciences, we should still care what it takes for there to be time in the folk sense (arguably the sense that is deployed in our understanding of deliberation and agency) and hence whether there is anything that answers to the folk concept of time. Showing that the unique groundability of temporal facts accords with our folk judgments about time shows that the phenomenon we are claiming to be uniquely groundable really is the phenomenon that the folk care about, and pick out by 'time'.

Consider the worlds in Figure 2.

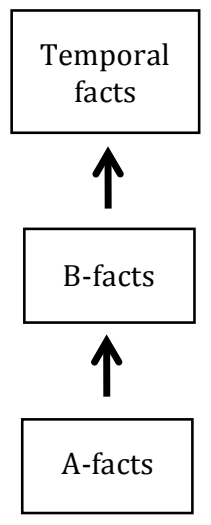

w1

Actual world

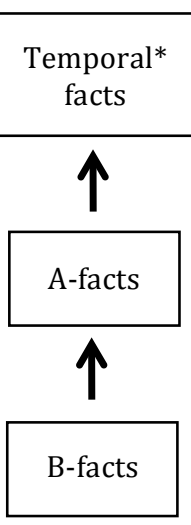

w2

Counterfactual world

Figure 2

The worlds in Figure 2 are similar to w1 and w2 from Figure 1. But, unlike Figure 1, Figure 2 represents that $\mathrm{w} 1$ is the actual world. If we are right and temporal facts are, necessarily, grounded by the same structured ground as they are actually, then it follows that w2 as represented in Figure 1 is impossible. There are worlds with the same structured ground as w2 as represented in Figure 1, but no such worlds are ones in which that structured ground grounds temporal facts. Instead, if w1 is actual then what is grounded in w 2 could be called temporal* facts. In labelling those facts temporal* facts, however, we do not wish to suggest that temporal* facts are really very much like temporal facts (the way XYZ is very much like water, as least superficially) but simply fail to be temporal facts because they lack the actual structured grounds of the temporal facts. As we discuss shortly, there is no reason at all to suppose that is so. We call the facts temporal* facts merely because they are the facts that exist at the same location in the grounding structure as do the actual temporal facts.

Alternatively, suppose that w 2 in Figure 1 is actual. We can represent this by Figure 3 . 


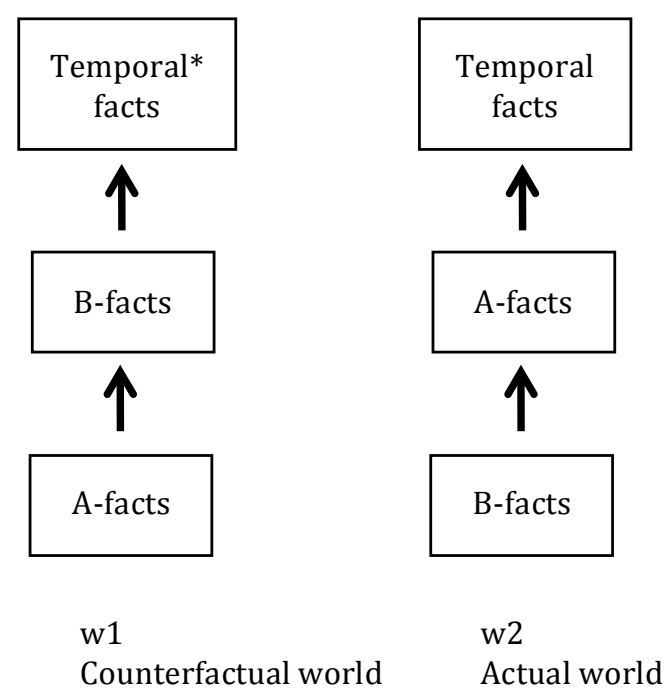

Figure 3

If w2 is actual then there is actually no objectively present moment, because temporal facts are grounded by $\mathrm{A}$-facts that are in turn underpinned by B-facts. The unique groundability of temporal facts entails that in all worlds with time, the temporal facts share this structured ground. ${ }^{28}$ Thus, we argue, if w2 is actual, then worlds like w1 are not worlds with time. This might seem objectionable, and we return to this issue shortly. First, however, one might wonder whether the actuality bias can be accommodated by something weaker than unique groundability.

For example, what if we demand not that temporal facts have the same structured ground in every world, but only that they have the same ground? That is: temporal facts are necessarily grounded by whatever grounds them in the actual world, but there can be different grounding relationships among those grounds in different worlds. This weaker restriction would not give us necessitarianism, since there are plausibly A-theoretic worlds and B-theoretic worlds in which temporal facts have the same ground. (For example: w1 and w2 in Figure 1.)

We think the weaker restriction does not go far enough, for roughly the same reason that we think it is not objectionable that w1 fails to count as containing temporal facts (and hence time) if w2 is the actual world (as represented in Figure 3). Insofar as the folk have an actuality bias-insofar as one thinks that time just is (within certain constraints) whatever is responsible for certain phenomena with which we are phenomenologically familiar, and necessarily so-one ought to find it plausible that this actuality bias extends to the total grounding structure. Thus, on proper reflection, one ought not find it plausible that w1 contains time, conditional on w2 being the actual world. Why think this?

Well, the intuition at play here is that time is the 'thing' with which we, here, are acquainted. It is the phenomenon that is responsible for our vast array of temporal phenomenologies. In w2 what ultimately grounds the temporal facts are the B-facts.

\footnotetext{
28 Note that unique groundability allows that there are some minimal features such that, were the folk to discover that the actual world lacks those features, they would conclude that there is actually no time. We are thus not forced to say that time exists no matter how metaphysically impoverished the actual world turns out to be: the folk's standards may only relax so far.
} 
Now consider w1, in which the B-facts ground temporal* facts, but they, in turn, are grounded by A-facts. If time is the thing we are actually acquainted with, then there is every reason to believe that the phenomenon with which inhabitants of w1 are acquainted is quite different to the phenomenon with which we in the actual world are acquainted. Indeed, we can have little reason to suppose that the phenomenon with which those in w1 are acquainted generates a phenomenology that is anything like ours.

To put it another way, return to our earlier discussion of the modal status of the A- and B-theories. We noted there that necessitarian standard A-theorists and necessitarian Btheorists agree that it is the role in the grounding structure that, in effect, defines what it is to be an A-fact or a B-fact. The necessitarian standard A-theorist thinks that there simply are no B-facts that are not grounded by A-facts: what it is to be a B-fact is to be so grounded. Likewise, the necessitarian B-theorist thinks that what it is to be an A-fact is to be grounded by the B-facts. By contrast, the contingentist thinks that we can have an independent grasp on these two notions (A-facts and B-facts) - independent, that is, of their place in the grounding structure. For the contingentist thinks that the very same B-facts can obtain in one world without being grounded by A-facts, and in another as a result of being grounded in A-facts. But it is not, we think, so very obvious that in each case we have are the very same B-facts being differently grounded. If actually the B-facts are not grounded in the A-facts, it is not obvious that a world in which there are A-facts which ground some set of facts (which for instance, describe an ordering) ought rightly to be described as the B-facts. Similarly, we think, if actually the B-facts ground the A-facts, then it is not obvious that in a world in which some putative A-facts are not grounded in the B-facts, we ought really to describe the former as "A-facts". For they bear little resemblance to the A-facts that are actually grounded in the B-facts: if they did, there would be little debate between the A- and B-theorist.

Thus we think it plausible that, in part, what defines what it is to be an A-fact or a B-fact is where that fact sits in the actual grounding structure. If actually, the A-facts ground the B-facts, then in worlds where the B-facts are what does the grounding, we should label the facts thus grounded as something other than A-facts. Likewise, if actually the A-facts ground the B-facts, then in worlds where something other than A-facts grounds the (alleged) B-facts, we should label the facts thus grounded as something other than Bfacts. For there is really little reason to suppose that what we have are the same facts, differently grounded, across worlds. And the same is true for the temporal facts themselves.

If our grasp of the concept of time comes via our phenomenology, then we should think that whatever it is with which those in w1 are acquainted, it does not deserve the label 'time'. After all (we are supposing), in the actual world it turns out there is no objective present or objective passage of time. In w1, however, there are facts consisting of monadic dynamical properties that ground facts consisting of static relational properties. We might have been inclined to say that the former are A-facts, and the latter B-facts. But, as we have just argued, if w2 is the actual world then we ought pay close attention to just how foreign counterfactual world w1 would be, and we ought to resist any such temptation; and we ought also to resist the temptation to say that what is grounded by those facts are temporal facts. ${ }^{29}$

\footnotetext{
${ }^{29}$ We wish to remain neutral about whether this means that facts concerning temporal topology are uniquely groundable. Nothing we have said here suggests that they are. It does not follow from any our principles of ground or from the unique groundability of temporal facts, that facts concerning temporal topology are themselves uniquely groundable. That is not to say that considerations similar to the ones we
} 


\section{Consequences for the $A / B$ debate}

Suppose one agrees with us that temporal facts are uniquely groundable. Then our arguments establish two conditional claims: if the actual world is A-theoretic, then all worlds with time are A-theoretic; and if the actual world is B-theoretic, then all worlds with time are B-theoretic. We thus have a pair of a priori conditionals, each with a potentially empirical antecedent and a modal consequent.

As a consequence, facts about the actual world take on greater metaphysical significance. The unique groundability of temporal facts amplifies arguments concerning the actual world across modal space: one can have reason to draw modal conclusions about the structured ground of time, based on empirical features of our world. For instance, perhaps one thinks that, given considerations arising from the special theory of relativity, A-facts are grounded by B-facts, and that B-facts are further grounded by some more global features of space-time. ${ }^{30}$ Or perhaps one thinks that, given considerations arising from quantum mechanics, there must actually be a preferred foliation of space-time, and therefore that B-facts are grounded by A-facts. ${ }^{31}$ Or perhaps one thinks that contemporary theories of quantum gravity show that actually, there is no time. ${ }^{32}$ Then one can conclude (respectively) that necessarily, the B-theory is true; or that necessarily, the A-theory is true; or that necessarily, there is no time. If our arguments succeed, then one important way to learn about modal space, vis-à-vis time, is to investigate the actual world.

Indeed, we think that not only can one come to learn about modal space by investigating the actual world, but one ought, in many cases, to focus on the actual world when attempting to come to conclusions about modal space. Of course, our claim is not that knowledge of the actual world is the only route to knowledge about modal space, in all cases: for example, if the A-series is logically inconsistent, then one can learn that the Atheory is necessary false, without knowing anything about the contingent features of actuality. ${ }^{33}$ Nevertheless, the conclusions of this paper make certain procedures for arriving at modal truths look epistemically dubious. For example, suppose that one accepts our claim that whichever theory of time is true, it is true of necessity. Then one might be tempted to reason in the following way. First, some particular theory of time, T, is possibly true. (To support this, one might appeal to intuition.) Thus, since whichever theory is true, it is true of necessity, $\mathrm{T}$ is necessarily true. But if $\mathrm{T}$ is necessarily true, then $\mathrm{T}$ is actually true. Therefore, $\mathrm{T}$ is actually true. Note that this argument schema runs from possibility to actuality: one begins by discerning the possibility of a view of time (perhaps via intuition); and then, since possibility implies necessity, which in turn implies actuality, one concludes that the view in question is actually true. We would like to stress that our conclusions do not licence such arguments, but instead undermine their usefulness. If we are right, then one ought only to be confident that the structured ground of the temporal facts is, necessarily, whatever it is actually. If one does not know the actual structured grounds of time, then one has little reason to be confident that one can correctly discern whether some allegedly possible structured ground of temporal

\footnotetext{
raise for thinking that temporal facts concerning temporal topology facts are also uniquely groundable.

${ }^{30}$ See for example Peterson and Silberstein (2010); Putnam (1967); Savitt (2000); Wuthrich (2011).

${ }^{31}$ Monton (2006); Sorkin (2006).

32 Barbour (1999); Andersen (2012); see also Baron, Evans and Miller (2010).

${ }^{33}$ For example, McTaggart famously claims that the A-theory is inconsistent (McTaggart 1908). Others including Dyke (2002); Smith (2011); Oaklander (1987) have followed.
} 
facts really is a possible structured ground of temporal facts. The argument schema in question is thereby unsuccessful: one ought not be confident that one of the premises is true (that $\mathrm{T}$ is possible) unless one is already confident that the conclusion is true (that $\mathrm{T}$ is actual). One can justifiably be confident that if the structured ground claimed by $\mathrm{T}$ is possible, then this is what grounds the actual temporal facts. But it does not follow that one can justifiably be confident that it's possible that the structured ground claimed by $\mathrm{T}$ grounds temporal facts.

Compare, for instance, the following reasoning. Suppose that one does not (yet) know the actual structured ground of water. Suppose that one can establish that water has, necessarily, whatever structured grounds it has actually. Then one might be tempted to claim-perhaps by appealing to intuition-that for some structured ground S, it is possible that water has S. One might then infer that water actually has S. But this would clearly be a mistake. After all, S might say that water is grounded by XYZ: given one's ignorance of the actual structured ground of water, this may well seem possible. The mistake here is to be confident that it's possible that water has S: since one doesn't know how water is actually grounded, one doesn't know how it is possibly grounded. The right thing to say, given one's ignorance of water's actual structured ground, is that water is necessarily grounded in whatever way it is actually grounded. If our arguments in this paper succeed, then the same applies to time. Therefore, the lesson of the paper is in part cautionary: it is not merely that we can come to learn modal truths by attending to empirical truths about our world; it is also that in many cases, this will be the only reliable way to come to learn modal truths of this kind.

\section{References}

Anderson, E. (2012) The Problem of Time in Quantum Gravity. In Classical and Quantum Gravity: Theory, Analysis and Applications. Vincent. R. Frignanni (Ed.), pp. 1-25 (New York: Nova).

Audi, Paul, R. (forthcoming). "A Clarification and Defense of the Notion of Grounding" in Fabrice Correia and Benjamin Schnieder (eds.) Grounding and Explanation, Cambridge: Cambridge University Press.

Balaguer, M. (1998). Platonism and Anti-Platonism in Mathematics. New York: Oxford University Press.

Barbour, J. (1999). The End of Time. Oxford; New York: Oxford University Press.

Baron, S., Evans, P., and Miller, K. (2010) From Timeless Physical Theory to Timelessness. Humana Mente, 13, 35-59.

Beebee, H and N Sabbarton-Leary (2010). "On the Abuse of the Necessary a Posteriori" in H Beebee and N Sabbarton-Leary (eds) The Semantics and Metaphysics of Natural Kinds. Routledge 159-79. 
Braddon-Mitchell, D. (2004a) "Masters of our Meanings". Philosophical Studies 118 (12):133-52.

Braddon-Mitchell, D. (2004b). "Folk Theories of the Third Kind”. Ratio 17 (3):277-293.

Braddon-Mitchell, D, (2009). "Naturalistic Analysis and the a Priori." In BraddonMitchell and R. Nola (eds.) (2009) Conceptual Analysis and Philosophical Naturalism. MIT Press.

Braddon-Mitchell D and F Jackson (1999). "The Divide and Conquer Path to Analytic Functionalism" Philosophical Topics 26(1-2): 71-89.

Butterfield, J. (1984). "Seeing the Present" Mind, 93, 161-76.

Callender, C. (2000). "Shedding Light on Time” Philosophy of Science 67: S587-S599.

Cameron, R. (2007). “The Contingency of Composition”. Philosophical Studies Vol.136, No.1 pp 99-121

Chalmers, D. (2004). "Epistemic Two Dimensional Semantics" Philosophical Studies; 118(1-2): 153-226.

Colyvan, M. (2000). "Conceptual Contingency and Abstract Existence" Philosophical Quarterly 87-91.

Colyvan, M. (2001). The Indispensability of Mathematics. OUP New York.

Dummett, M. (1960). "A Defense of McTaggart's Proof of the Unreality of Time" Philosophical Review 69 (4):497-504.

Dyke, H. (2002). "McTaggart and the Truth about Time". In In Craig Callender (ed.), Time, Reality and Experience. Cambridge University Press.

Fine, K. (2005). "Tense and Reality" in Kit Fine (ed.), Modality and Tense. Oxford University Press.

Field, H. (1993). "The Conceptual Contingency of Mathematical Objects" Mind 102(406): 285-299.

Jackson, F. (1998). From Metaphysics to Ethics. A Defence of Conceptual Analysis. Clarenden Press.

Jackson, F. (2004). "Why we need A-intensions.” Philosophical Studies. 118(1-2): 257-277

Jackson. F. (2007). "Reference and Description from the Descriptivists' Corner." 
Philosophical Books 48 (1):17-26.

Jackson, F. (2009). "A Priori Biconditionals and Metaphysics in David Braddon-Mitchell \& Robert Nola (eds.), Conceptual Analysis and Philosophical Naturalism. MIT Press.

Johnston, M. (1997). "Manifest Kinds". Journal of Philosophy 94(11): 564-583.

Lewis, D. (1966). "“An Argument for the Identity Theory” Journal of Philosophy, LXIII, pp. 17-25; reprinted in Philosophical Papers Volume I, Oxford Univ. Press, Oxford, 1983, pp. 99-107, page references hereafter are to this edition.

Mc'Taggart, J. E. (1908). The Unreality of Time. Mind, 17(68), 457-474.

Mellor, D. H. (1998). Real Time II, London: Routledge.

Mellor, D. H. (1981). Real Time. Cambridge University Press.

Miller, K. (2009) “Defending Contingentism in Metaphysics” Dialectica 62(1) pp 23-49

Miller, K (2010) “Three routes to contingentism in metaphysics" Philosophy Compass 5(11) pp 965-977.

Monton, B (2006). "Presentism and Quantum Gravity" In Dennis Dieks (ed). The Ontology of Space-time. Elsevier.

Moxersky, J.M. (2000). “Time, Tense and Special Relativity." International Studies in the Philosophy of Science 14(3): 221-236.

Oaklander, L. Nathan. (1987). "McTaggart's Paradox and the Infinite Regress of Temporal Attributions. Southern Journal of Philosophy 25 (3):425-431

Parsons, J. (2006) 'Conceptual conservatism and contingent composition'. Unpublished.

Peterson, D. and Silberstein, M. (2010). Relativity of Simultaneity and Eternalism: In Defense of the Block Universe. In Vesselin Petko (ed.). Space, Time and Space-time: Fundamental Theories of Physics. Volume 167, part 2, 209-237. Berlin: Springer.

Phelan, M and W Buckwalter (2012). "Analytic Functionalism and Mental State Attribution" Philosophical Topics 40(2): 129-154.

Price, H. (unpublished). The Flow of Time.

Price, H. (1996). Time's arrow \& Archimedes' point: new directions for the physics of time (Vol. New). New York: Oxford University Press. 
Putnam, H. (1967). Time and Physical Geometry. Journal of Philosophy 64, 240-247.

Rasmussen, J. (2015). “Tenseless Times”. Philosophical Studies 172(12): 3221-3227

Savitt, S. F. (2000). There's No Time Like the Present (in Minkowski Spacetime). Philosophy of Science, 67, Supplement. Proceedings of the 1998 Biennial Meetings of the Philosophy of Science Association. Part II: Symposia Papers, 563-74.

Schaffer, J. (2009). On What Grounds What. In D. Chalmers, D. Manley and R. Wasserman (Ed.), Metametaphysics, (pp. Oxford: Oxford University Press.

Smith, N.J.J. (2011). "Inconsistency in the A-theory." Philosophical Studies 156 (2):231 247.

Sorkin, Rafael. 2006. Geometry from order: causal sets. In Einstein Online 02, 1007.

Stroud, B. (2000). The Quest for Reality: Subjectivism and Metaphysics of Colour. OUP.

Tallant, J. (2012). “(Existence) Presentism and the A-theory” Analysis 72 (4): 672-681.

Trogdon, Kelly (forthcoming). "An Introduction to Grounding" in M. Hoeltje, B. Schnieder, and A. Steinberg (eds.), Basic Philosophical Concepts, Munich: Philosophia Verlag.

Wüthrich, C. (2011). The Fate of Presentism in Modern Physics. In Robert Ciuni, Kristie Miller and Giuliano Torreng (eds.). New Papers On The Present - Focus On Presentism. Munich: Philosophia Verlag.

Zimmerman, D. (2008) "The privileged present: Defending the A-Theory of time" in Theodore Sider, John Hawthorne \& Dean W. Zimmerman (eds.), Contemporary Debates in Metaphysics. Blackwell Pub..211-226.

Zimmerman, D. (2005) "The A-theory of time, the B-theory of time and "Taking Tense Seriously" Dialectica 59(4): 401-457. 